\title{
HOW ISIZULU SPEAKERS USE COHESION IN THEIR ACADEMIC WRITING IN ENGLISH
}

\author{
Andrew Drummond, King's College London, United Kingdom
}

Achievement rates for black students in South African higher education remain low after 20 years of democracy. Writing academic English according to existing conventions is a complex skill. One aspect of this skill is producing cohesive text. In this article, the writing of a group of isiZulu speakers at Wits is analysed to determine how Hallidayan cohesion is operating therein: how does this language group use conjunctions, lexical cohesion, referencing, ellipsis and substitution when writing in English? From this analysis, it is evident that there are elements of referencing, conjunction use and lexical cohesion which are well developed in their writing. At the same time, evidence of speech-type syntax in the data indicates areas where further development is possible. These findings have led to suggestions on how academic language input could facilitate writing skills development for this language group.

\section{INTRODUCTION}

Statistics on rates of achievement for various linguistic groups in South Africa point to a persisting inequality. Letseka and Maile (2008: 4) state that 'black Africans and coloureds ... continue to lag behind in education success rates' and that $30 \%$ of learners drop out in their first year of study at university, with a further $20 \%$ discontinuing in their second and third years. Ultimately, '[only] $22 \%$ graduated within the specified three years duration for a generic Bachelor's degree' (Letseka \& Maile, 2008: 5). Language is a key issue throughout the educational process. While only $9.6 \%$ of South Africans speak English as their first language (Statistics South Africa, 2011), they make up 32\% of university enrolments (Ministry of Education, 2002), a number that far outstrips English speakers' demographic presence in the country. Butler and Van Dyk (2004: 1) summarise this advantage thus: 'If one specifically considers the correlation between the numbers of first- and second-language speakers of English who register at universities in South Africa ... it is apparent that a significantly larger proportion of mother tongue students are successful.'

Once at university, students are expected to produce longer essays in English, conforming to various academic writing conventions. Achieving mastery of academic discourses might be troublesome for South African matriculants who may have only been exposed to limited reading and writing practice at high school (Taylor \& Vinjevold, 1999). In fact, ClarenceFincham (2000) suggests there a large number of South African students start university with insufficient reading and writing skills in English and all other languages. Gaining proficiency in academic writing conventions, then, may require considerable exposure to academic texts, along with overt instruction in and sustained practice with their key linguistic features in order to achieve mastery of these conventions.

English academic writing is formal; it contains more frequent use of passive verbs (Biber, 1993); it contains more impersonal grammatical subjects such as 'it' and 'there'; it is lexically denser than speech and contains more frequent nominalisations (Fang, Schelppegrell \& Cox, 2006); there are fewer categorical statements and there is more hedging (Hyland, 1994); the argument of the text develops in a linear fashion, avoiding repetition; and the text is 
constructed cohesively with conjunctions, references, lexical items and ellipsis (Halliday \& Hasan, 1976). Research could profitably be conducted into how South African students are using each of these features in their academic English. The focus of this research, however, is on how cohesion is being used in isiZulu speakers' writing in English.

Effective cohesion is an important part of academic writing. According to Cox, Shanahan and Sulzby (1990: 49), 'cohesion is important both to the reader in constructing the meaning from a text and to the writer in creating a text that can be easily comprehended.' Cohesion in writing is complex, with some antecedents in speech (Halliday \& Hasan, 1976) but with particular conventions in written forms of the language; it is central to writing in an economic style and avoiding redundancy. Cohesion, in the form of conjunction, allows for explicit signposting of how the text is developing as required by written English academic discourse. Knowledge of this system of linguistic conventions can facilitate the clear construction of meaning within a text and the development of an argument.

Writing centres, such as Wits School of Education Writing Centre, have been developed in South African universities with a view to facilitating the development of the skills that will lead to achievement at tertiary level. IsiZulu is both the most frequently spoken home language in South Africa, with as many as $22.7 \%$ of households using it (Statistics South Africa, 2011: 29), and the most widely spoken home language in Gauteng, with almost 20\% of households using it (Statistics South Africa, 2011: 30). Insights from an investigation into the language use of this particular group could help to inform the content of academic language courses for isiZulu speakers at Wits and other institutions so that a more relevant scaffolding process benefitting isiZulu speakers might emerge.

However, there is a debate about to what extent support given to help develop students' writing should be focused on acquiring knowledge of generic academic language and texts that might prove useful for a variety of academic disciplines (Wingate \& Tribble, 2012) and to what extent it should focus on 'socialising' students into the discourses connected to specific academic disciplines (Lea \& Street, 2006). For the purposes of this paper, it is assumed that both forms of input could potentially be useful, but it is anticipated that the type of data generated by the present study will inform input focusing on academic language. For this reason, the term 'academic language input' is favoured over 'academic literacy' in this paper.

\section{RESEARCH QUESTIONS}

The following are the key research questions investigated in this paper:

1. How do isiZulu-speaking undergraduates use conjunctions, lexical cohesion, referencing, ellipsis and substitution when writing in English?

2. What do the data suggest about whether academic language input could promote writing skills development for this group?

3. If required, what form might such academic language input take?

\section{LITERATURE REVIEW}

Halliday and Hasan (1976: 4) explain how cohesive elements in a text are related to one another by showing that some textual elements cannot be interpreted correctly without reference to others. These elements work together to form a cohesive relationship which serves to create a sense of integration in the text, e.g., by employing 'the cross-referencing Per Linguam 2017 33(2):76-93 http://dx.doi.org/10.5785/33-2-700 
function of pronouns, articles and some types of adverbs' (Crystal, 2011, cohesion entry). The cohesive use of pronouns, articles and so on are needed as 'glue' because relations between various clausal elements within a text cannot be established by grammar alone (Halliday, 1994: 288). Halliday and Hasan's seminal analysis of cohesion sets out the following aspects in English: conjunction, reference, ellipsis, substitution and lexical cohesion. A brief description of each of these categories follows.

Conjunctions are functional words in a sentence which link clauses and show the relationship between them. For Halliday and Hasan (1976: 5), 'cohesion is partly expressed through grammar and partly expressed through vocabulary', and '[conjunction] is on the borderline between the two' (Halliday \& Hasan, 1976: 6). This is because conjunctions carry a lexical meaning along with a syntactic demand on the language surrounding them. For example, 'however' indicates that the following clause, sentence or paragraph will be in contrast to or concede something that has gone before, achieving this through its semantic properties, but requires that the contrasting/concessionary information is not in the same sentence as itself, thereby exercising a syntactic influence on the text. Halliday and Hasan (1976: 242) subdivide the category of conjunctions into the following classifications according to how they order and interrelate the text around them: additive, adversative, temporal and causal.

Reference is the use of pronouns, possessives and determiners mostly used to refer back to previous text. For instance, in: 'My brother loves his wife,' we perceive a tie between 'my brother' and 'his'. This looking back to previous text is known as anaphoric reference and is more common than the forward-looking cataphoric reference. Halliday and Hasan (1976: 324) also classify the definite article as establishing referential cohesive relations in texts.

Ellipsis is used to avoid redundancy in writing, when we can leave out material which can be clearly inferred by the reader. Consider the following sentence: 'We investigated attitudes in order to discover who would be willing to volunteer and who wouldn't.' The words 'be willing to volunteer' are ellipted from the end of the sentence but are inferred by the reader from the limited range of interpretative possibilities at that point in the text.

Substitution occurs when a word, phrase or clause is replaced by another word to avoid its repetition. In the following example: 'Do you want this book?' 'No, I want the other one,' it is evident that 'one' replaces 'book'. Equally, the predicate can be substituted as in the following: 'Shall we drive all the way to Cape Town this weekend?' 'Yes, let's do so,' where 'do so' replaces the words denoting the proposed action.

Lexical cohesion is used to avoid repetition of nouns in a text, and to add additional information. A proper noun, noun or noun phrase may be referred to by alternate wordings or synonyms as the text develops. For instance, 'David Beckham' may be later referred to as 'the father of four' or 'the former England Captain' as the text develops, with each reference providing additional information as required. Stotsky (1983: 437) attributes a writer's ability to set up lexical ties as 'lexical maturity' and 'stylistic flexibility'.

These five aspects of cohesion present in Halliday and Hasan's (1976) work have been used by researchers to investigate languages other than English, such as French (Jisa, 2004), Arabic (Mohamed-Sayidina, 2010) and Spanish (Gutierrez-Clellen \& Heinrichs-Ramos, 1993). Ndlovu's (2013) investigation into referential cohesion in isiZulu translated health texts is one of the only studies available on cohesion in isiZulu. Many of his observations about cohesion in isiZulu are pertinent to this research in that they provide information on the differences

Per Linguam 2017 33(2):76-93

http://dx.doi.org/10.5785/33-2-700 
between the systems of cohesion in English and isiZulu. For example, on the reference category of cohesion, Ndlovu (2013: 352) shows that, 'in Zulu, the third-person [subject] pronouns (he/she) are expressed by the concord u-.' Interestingly, Makalela (2007: 140) has found that 'conflation of masculine pronouns with feminine pronouns and vice-versa is a prominent feature among non-native English speakers.' Furthermore, Ndlovu (2009: 104) shows that there is a comprehensive system of concords for each noun class, allowing referential pronouns in English to be translated and retain their referential function. Ndlovu (2013) asserts that aspects of referential cohesion across the two languages can be regarded as 'a problem that needs attention since isiZulu is structurally different from English.' Nzama (2010) gives the following example of this: 'Umfana yena akakufuni ukudla ... could be literally translated as: The boy he does not like food.' In addition, Nzama (2009: 107) explains that the definite article, which according to Halliday and Hasan is commonly used in referential cohesion in English, is not present in isiZulu, but that determiners such as 'lokhu' (this) can be used in their place (Nzama, 2013: 356). His work shows examples of 'lokhu' as the grammatical subject of the sentence with no accompanying noun, as 'this' would do in English. In his PhD thesis, Ndlovu (2009: 159, 168) gives examples of lexical reference chains in texts translated into isiZulu.

In the category of substitution, Ndlovu (2009: 57) shows that nouns can be substituted in written texts. He also gives examples of ellipsis where nouns are ellipted but suggests that repetition may be employed more frequently in isiZulu than English (Ndlovu, 2009: 58). Repetition has an important role in some traditional forms of narrative in isiZulu. Hlongwane and Naudé (2004: 15) state that 'repetition is a favourite stylistic device in Zulu praise poems (izibongo) and traditional narratives (izinganekwane) .... the lexical item may be repeated two or more times in order to heighten the communicative impact.' This repetition device noted of the oral traditions, if applied to academic writing in English by transference, might lead to texts exhibiting relatively infrequent instances of lexical cohesion through synonymy.

Other types of speech-type syntax appearing in academic writing are also possible. Gee (1990) explains that speech occurs faster than writing and is therefore more fragmented and 'less syntactically integrated'. Due to the amount of time writers have to craft their texts, they can make use of resources that speakers do not have time to employ such as 'nominalisations, participles, attributive adjectives and various subordinating clauses' (Gee, 1990: 75). In terms of Halliday and Hasan's (1976) model of cohesion, identifying speech-type syntax would entail exploring the arrangement of clauses to see how they are linked with conjunctions. The research methodology set out below seeks to explore whether these aspects of speech-type syntax cohesion occur in the writing of this group.

Ndlovu's (2013) valuable study has provided starting points from which to investigate the academic writing of isiZulu speakers writing in English, especially with regard to whether the features of isiZulu listed above cause transference errors to occur. Some studies have been carried out to explore the potential influence of the cohesion system of one language influencing another, such as Mohamed-Sayidina's (2010) investigation of whether features of Arabic cohesion appear in Arabic speakers' English writing. However, there are apparently no published research papers exploring this area for isiZulu speakers writing in English, and it is hoped this study may be a contribution in that regard.

Per Linguam 2017 33(2):76-93

http://dx.doi.org/10.5785/33-2-700 


\section{RESEARCH METHODS}

The participants for this research were isiZulu majors in their second year of the BEd programme at Wits University; ethical clearance for the study was given by the University. While these students are often multilingual, they have identified isiZulu as their primary language. The choice to focus on isiZulu speakers over other linguistic groups was based on their being the most numerous linguistic group on campus and in Gauteng more broadly. In the second year of the BEd, around 60 students opted to take isiZulu as their major. All of the papers from members of this cohort whose first language was self-identified as isiZulu and whose examination papers were available in the college storage facility were used for the study; there were 23 papers in total. This group of 23 represented a mix of students from KwaZulu-Natal and Gauteng.

The 23 papers were written in June 2014 as part of a summative examination for the New Literacies for Teachers module. The students were given four articles on using technology in the classroom to read prior to writing the examination. The examination question asked students to comment on the advantages and disadvantages of technology use in the classroom. The articles were intended to allow them to include ideas and citations in their written examination paper in the construction of an argument in response to the title. The assessment of the cohesion in these papers set out below recognises that the cohesion of an essay drafted and written over a longer period is likely to be substantially more developed than the cohesion evident in an essay written under examination conditions.

\section{Research instrument}

These 23 scripts were analysed to see how features of reference, conjunction, lexical cohesion, substitution and ellipsis were operating according to the following questions:

\begin{tabular}{|c|c|}
\hline $\begin{array}{l}\text { Type of } \\
\text { cohesion }\end{array}$ & Researcher's questions about the text \\
\hline Reference & $\begin{array}{l}\text { - How has the writer used pronouns anaphorically to refer to earlier } \\
\text { instances of the noun? } \\
\text { - What kind of referencing is present in the text? E.g., are there } \\
\text { references comprised of [determiner + noun] such as 'this issue' or } \\
\text { [conjunctions + reference] such as 'because of this'? } \\
\text { - Is the definite article used accurately? }\end{array}$ \\
\hline Conjunction & $\begin{array}{l}\text { What are the relative frequencies of additive and adversative } \\
\text { conjunctions in the text? } \\
\text { - What are the relative frequencies of coordinating and subordinating } \\
\text { conjunctions in the text? } \\
\text { - Is the writer aware of the syntactic conventions required by the } \\
\text { conjunction he/she has used? } \\
\text { - Has the writer chosen the conjunction correctly according to its } \\
\text { meaning in English? }\end{array}$ \\
\hline $\begin{array}{l}\text { Lexical } \\
\text { cohesion }\end{array}$ & $\begin{array}{l}\text { - How has the writer used synonyms and hyponyms in creating lexical } \\
\text { cohesion? }\end{array}$ \\
\hline Ellipsis & - How has ellipsis been used in the text? \\
\hline Substitution & $\begin{array}{l}\text { - Are there examples of substitution in the text? } \\
\text { - How has this been done? }\end{array}$ \\
\hline
\end{tabular}

Per Linguam 2017 33(2):76-93

http://dx.doi.org/10.5785/33-2-700 
Instances of cohesive phenomena were recorded in each category in the following way: each script was read a number of times, marking reference words and conjunctions used accurately and inaccurately. Then, instances of lexical chains in the texts were identified and highlighted in a separate colour. Finally, the texts were re-read and instances of ellipsis and substitution were noted. Once all the scripts had been marked in that way, the number of instances of each feature of cohesion across the entire dataset was calculated and this information was added to a table. Please see below for samples of scripts marked according to this methodology. Compiling data in this way afforded, for example, a direct comparison of the number of subordinating and coordinating conjunctions in the texts and a juxtaposition of accurate uses of the definite article along with inaccurate uses, among other contrasts. In this way, the data provided knowledge of how various areas of cohesion are functioning in the isiZulu speakers' written English. Where there were noticeable patterns of good practice and areas for development, these informed decisions on what the most appropriate content for academic language input might be.

\section{DATA ANALYSIS}

In the following section, where language is quoted from students' texts it has not been corrected.

\section{Reference: the definite article}

Accurate usage of the definite article in English is considered to be a difficult area for speakers of BSAE (Walt \& Rooy, 2002: 121) and this dataset confirmed this to an extent.

\begin{tabular}{|l|c|c|c|}
\hline & $\begin{array}{c}\text { No. of articles used } \\
\text { correctly }\end{array}$ & $\begin{array}{c}\text { No. of missing } \\
\text { articles }\end{array}$ & $\begin{array}{c}\text { No. of zero articles } \\
\text { required }\end{array}$ \\
\hline Totals & 264 & 17 & 36 \\
\hline
\end{tabular}

In total, there were 264 correct uses of the definite article noted in the 23 papers. Since 16 of the 23 writers made at least one mistake with definite articles, there may be a case for some input in this area. The most noticeable pattern of error occurring in the data was a tendency to use a definite article when a 'zero' article would be expected in standard English. 'Zero' articles indicate a noun being used in a generalised sense rather than as a mention of a noun previously acknowledged by the writer. The dataset showed this type of error in 13 out of 23 papers. Here is an example of the writer overgeneralising article use, from the opening line of the essay.

\section{'Technology plays an important role in learning in the classrooms' (paper 6).}

Since this is the first line of the script, it is too early to be referring to a specific, known or limited set of classrooms and seems, therefore, to be a case where the zero article would be accurate. The following example shows the zero article operating correctly:

'I am against the use of ${ }^{\wedge}$ technology at ${ }^{\wedge}$ school' (paper 22).

Also occurring at a slightly lower frequency was the absence of the article where one would be required, as in the following example:

'Technology should not be used in ^ classroom' (paper 16).

Per Linguam 2017 33(2):76-93

http://dx.doi.org/10.5785/33-2-700 
While there were only 17 cases of absent articles across the whole dataset, this type of error was present in nine of the papers. To a certain extent, the definite article's accurate referential use had been acquired by these undergraduates, with some still making errors in this area.

\section{Reference: pronouns}

The dataset also provided a picture of how accurately references with pronouns were used. Every paper in this dataset contained pronouns used referentially with a high level of accuracy. Here are some examples of the successful use of pronoun referencing from one paper:

'Technology plays an important role in the classroom as it brings about new and effective changes in the education system' (paper 13).

'Nowadays, cellphones are widely used our society, thus they must be allowed in schools' (paper 13).

There were very few pronoun errors across the dataset:

\begin{tabular}{|l|c|c|c|}
\hline & Double subject & Singular/plural agreement error & Ambiguous reference \\
\hline Totals & 5 & 4 & 0 \\
\hline
\end{tabular}

A specific transfer error that is thought to occur frequently for isiZulu speakers is adding a pronoun as a second reference to the subject of a sentence. However, double subjects did not appear as a very significant issue in this dataset. In fact, only five cases of such a structure were noted in this set. Here is an example from this limited set of errors:

'I firmly believe that technology it is a distraction towards learning in the classroom' (paper 23).

In addition, there were only four singular/plural agreement errors in the data set where a pronoun, such as 'it', was used to refer to a plural noun instead of 'they' or 'them', as in the following example:

'People in developing countries have developed love for mobile phones, some are using it for learning and other entertainment' (paper 16).

The conflation of male and female pronouns did not appear as an issue in this dataset, but given the relative infrequency of gender-specific references in this type of argumentative essay, this was too small a data sample to be informative. Generally, given the very low number of errors in this area and the consistently accurate use of pronouns, the overwhelming impression afforded by the data is that this aspect of cohesive referencing in English was largely acquired by these undergraduates.

\section{Reference: determiner references}

The determiners this, that, these and those are powerful cohesive tools that allow references to be made into longer ideas in aforementioned text, reducing redundancy that can occur through repetition. The following table shows of the use of the above determiners in the first dataset. The final column indicates those references whose referents were ambiguous: 


\begin{tabular}{|l|c|c|c|c|c|c|}
\hline & This & That & These & Those & Other & Ambiguous references \\
\hline Totals & 18 & 9 & 1 & 3 & 0 & 7 \\
\hline
\end{tabular}

In total, there were 31 instances of determiners used as cohesive reference items across the data sample. Seven of these 31 instances were ambiguous references. In addition, there were no determiner references in eight of the 23 papers; almost a quarter of the determiner-based references in the dataset. The low total and high proportion of ambiguous references indicates capacity for development in this area. Here is an example of 'this' used to link ideas where the reference is clear to the reader:

'When learners are allowed to use cellphones in the classroom discourse this can be a good thing to learners as they will not be writing but typing' (paper 24).

The following is an example of 'this' where the reference is inexplicit:

'Technology must be questionable to all us in terms of usage. It must not be exposed to learners too much they should learn to answer on their own. This could lead them in problems not to think on their own' (paper 18).

It is probable that 'this' refers to 'unrestricted access to technology', but it requires the reader to volunteer the probable coherence to the text when a more explicit reference would require less decoding. A methodology for academic language input would be to explore the possible influence of deitic references from speech creating ambiguity in the undergraduates' writing.

\section{Reference: determiner + noun}

[Determiner + noun] references are powerful devices for replacing longer stretches of text with lexical economy and very specific linking. For example, the use of 'this problem' in the following fabricated example illustrates the ability of the [determiner + noun] device to replace much longer stretches of text, quite differently from the action of personal pronouns:

The rand is losing value against many other internationally traded currencies.

This problem is making it difficult for South Africans to travel to some countries.

Instances of [determiner + noun] references from the papers have been included in this section on reference, although this device represents aspects of reference and lexical cohesion. In fact, Halliday and Hasan (1976: 85) state that 'there are many instances of cohesive forms which lie on the borderline between two types and could be interpreted as one or the other.' The following table shows those instances of such [determiner + noun] combinations found in this dataset:

\begin{tabular}{|l|c|c|c|c|c|}
\hline & This + noun & That + noun & $\begin{array}{c}\text { These }+ \\
\text { noun }\end{array}$ & $\begin{array}{c}\text { Those }+ \\
\text { noun }\end{array}$ & $\begin{array}{c}\text { Ambiguous } \\
\text { references }\end{array}$ \\
\hline Total & 4 & 4 & 14 & 4 & 1 \\
\hline
\end{tabular}

It was notable that there were fewer ambiguous references when the writer had used a noun following the determiner than in the previous section where determiners were by themselves. In fact, only one of the 26 instances here were ambiguous. This increased success at creating explicit references with the [determiner + noun] combination indicates that those students 
having difficulty creating explicit links could benefit from adding an accompanying noun instead of writing a single determiner. References comprising [determiner + noun] were noted in 12 out of the 23 scripts assessed. Most were linking by repeating the first instance of the noun, as in the following example:

'Technology can help answer many basic questions. A teacher cannot always have the correct answer to give to the learners, therefore, technology play a vital role in answering those questions' (paper 1).

The instances of [determiner + noun] referencing in this dataset were notable for the relative absence of the use of abstractions to refer to whole ideas mentioned in earlier parts of the paragraph. In other words, they were not yet fully realised as a resource to produce lexically dense text as the nouns are not used to substitute for longer stretches of text. The following fabricated example shows how this can be done:

Garcia (2007) states a firm belief that relaxing school policies to permit bilingual children to communicate with resources from both languages will allow a broader access to knowledge. This idea is resisted in some quarters, however.

Only three [determiner + noun] references in the 23 papers were recorded where the abstraction of the noun went beyond either a repetition or a synonym for an earlier noun. Here is one of those examples:

'Miller states: “... We must assess the implements available for each specific discipline ...". What I understand about this statement is that we should not rely on technology' (paper 6).

Here, this use of the [determiner + noun] combination provides an authorial comment on a citation. The low frequency of such linking points to an opportunity to raise awareness of [determiner + abstract noun] combinations as part of academic language input providing the linguistic means to summarise earlier text and concisely comment on citations. Drummond's (2016) list of high frequency abstract nouns used in this way in academic language could be useful for this purpose.

\section{Conjunctions: overall}

The table below shows to what extent conjunctions have been used in the texts for cohesive purposes. The additive and adversative conjunctions noted here refer not only to items linking two clauses in the same sentence, but more broadly to discourse markers such as 'however' and 'on the other hand' operating beyond the sentence level. Coordinating and subordinating conjunctions, however, were only noted when providing relations between clauses in a sentence. The final two columns contain the number of syntactic and semantic errors arising in the data. A striking thing about this global dataset is the low number of errors pertaining to conjunction use in the texts:

\begin{tabular}{|l|c|c|c|c|c|c|}
\hline & Additive & Contrastive & Coordinating & Subordinating & $\begin{array}{c}\text { Syntax } \\
\text { errors }\end{array}$ & $\begin{array}{c}\text { Semantic } \\
\text { errors }\end{array}$ \\
\hline Totals & 225 & 47 & 235 & 182 & 22 & 6 \\
\hline
\end{tabular}




\section{Conjunctions: additive vs adversative conjunctions}

Analysis of individual papers showed that some writers' use of adversative conjunctions was very limited or non-existent. Of the 23 papers, five had no adversative conjunctions at all; five of the papers contained one adversative conjunction and the remaining 13 displayed a range of between two and seven instances. A reason for noting the distribution of additive versus contrastive conjunctions in the undergraduates' writing is that the presence of adversative conjunctions can be a sign that the writer has consciously included counter claims in their argument. Significantly, the five papers that did not contain any adversative conjunctions did not contain any counter-arguments either. Additionally, none of the five papers with only one adversative conjunction contained a substantial counter-argument. To a significant extent, then, the absence of adversative conjunctions in this dataset also corresponded with the writer's argument being one-sided. Academic language input could combine the presentation of adversative conjunctions with illustrations of how they signpost the development of a counter-argument.

\section{Conjunctions: coordinating vs subordinating conjunctions}

As the table above shows, coordinating and subordinating conjunctions appeared at similar rates across the scripts. These data included the use of 'and' as a branching device, but if these instances were removed, the count would be noticeably in favour of subordinating conjunctions. At times, some writers evidenced control in the weighting of clauses with the use of subordinate conjunctions, as in the following example where the clause given emphasis is underlined (paper 8):

\section{'Although digital cellphones might be seen as a disruption in a classroom situation, not all of the users use it for only one purpose of having fun browsing through the internet.}

At the same time, though, both coordinating and subordinating conjunctions were often situated in longer run-on stretches of writing that gave the writing a speech-type syntax. Runon sentences also made it difficult, at times, to assess the relative importance the writer was giving to various clauses within the sentence. As Halliday states (Halliday \& Hasan, 1976: 222): 'In a paratactic clause complex, the clauses have equal status.' In fact, nine of the 23 papers had at least one long section of run-on language, connected by several conjunctions. Here is an example of this:

'When you use technology in class you are not doing something that is wrong because technology is essential in [our] class today as we make use of cell phones in class not to chat while the teacher is teaching but doing academic work such as reading on libraries using our cell phones' (paper 3).

Here, the writer used both subordinating and coordinating conjunctions to connect clauses to form a very long sentence. These kinds of constructions have a speech-type syntax since, in speech, clauses can follow on from one another indefinitely without formal punctuation. This type of syntax could be addressed with input on the use of subordinate clauses, providing the writer with tools to reformulate speech-type thought into a written framework that gives prominence by carefully structuring what goes into the main clause and the subordinate clause.

Per Linguam 2017 33(2):76-93

http://dx.doi.org/10.5785/33-2-700 


\section{Conjunctions: semantics and syntax}

The data showed a large proportion of semantically and syntactically accurate conjunctions. In fact, there were only six occurrences of a conjunction failing to link the text semantically so that it is easily decodable by the reader. The following shows a rare error in selecting a conjunction inaccurately in terms of its meaning. Here, the writer began a new paragraph with 'for example' when 'however' would have provided the required contrast.

'... the teacher can never be sure the learners are not off context if a technology it is allowed in the classroom. To keep track of that will be hard and time consuming.

For example, when learners are allowed to use cellphones in the classroom discourse this can be a good thing to learners' (paper 23).

Given how rare such errors were, though, these cohesive resources, used with great semantic accuracy, represent an excellent foundation. The syntactic type of error, however, was more frequent than the semantic. In fact, 22 instances of non-standard syntactic relations around the conjunction were recorded. Syntactic errors seemed to correspond, at times, with difficulties with sentential boundaries. Here is an example of a sentence being divided into two clauses, where the second clause lacks a subject and a verb, making it a fragment:

'So let's rather use computers in classrooms for the beneficial purposes and research purposes. Than have the top of the art schools with all technological equipment you can find but not producing the satisfactory results at the end of the academic year' (paper 2).

While Simmons (2015) explores how fragments can be used intentionally for meaningmaking, it seems that this approach seems has yet to gain any currency in academic writing. Linell (2004: 5) notes that speech forms are dynamic, continuously developing and free of punctuation. Punctuation difficulties may be understood, then, as a need for input on how to transform speech type structures into a textual form which adheres to the conventions of the written mode. With this in mind, academic literacy input could involve providing samples of texts with fragments and asking students to restructure the language.

\section{Conjunctions used with determiners and nouns}

While the vast majority of conjunction usage in the scripts demonstrated a robust acquisition of their meanings and syntactic conventions, there were very few examples of [conjunction + determiner], [determiner + linking verb + conjunction] constructions. These types of constructions have been dealt with in the conjunctions section, although they can be formed with elements of lexical cohesion, determiner referencing and conjunctions. The following examples illustrate the kind of linking made possible by such combinations:

1. The pass rate has risen every year since the introduction of the new assessment. Because of this, the school has regarded its introduction as an unqualified success.

2. For years, women were prevented from voting. Despite this policy, the influence can be seen in the political life of the nations in other ways.

3. The roads were almost empty. This was due to the number of people watching the game. 
Only two examples of these kinds of combination were used accurately in the scripts and there were two more uses where the syntax around the phrase was not resolved. Here is one of the correct uses:

'I agree with Miller's argument that teachers must find a way to accept the use of technology in classrooms. This is because, there is a large number of things teachers and students will benefit' (paper 13).

Since many of these cohesive phrases establish causal and adversative relations between sentences, they are useful in constructing an argument. They are also very common when constructing a sequential progression between two sentences. The relatively low frequency of such linking in the scripts points to the relevance of developing such explicit linking as part of academic language input.

\section{Lexical cohesion}

The two most common lexical chains appearing in the papers may be classified by the following superordinate terms: 'technology' and 'learner(s)'. The following data set out to what extent these terms were varied through the use of synonyms by the writers in the course of developing a lexical chain within their essays.

\section{Lexical cohesion: exploring the term 'technology'}

In all the papers reviewed, the lexical item 'technology' acted as a superordinate term, i.e., the central, most general term from which its synonyms and related terms are derived. The lexical item 'technology' was widely repeated in the scripts, with an average number of around seven repetitions per paper and a range of between and three and 12 repetitions per paper. Typically, as the writer moved from general statements to more specific claims and evidence, particular forms of technology appeared in the texts. Stotsky (1983: 435) notes this tendency 'for a general concept to precede the discussion of examples or aspects of the concept' is typical of essay writing in English. Most writers in this sample of 23 demonstrated the capacity to move from the general to the specific fluently. Here is an example of such a move into hyponymy commensurate with the text's shift from the general towards the specific:

'Through technology can be in touch with school based knowledge wherever we are. We do not need to be sitting with a textbook to learn and to prepare for the next lesson or to learn for a test because our cell phone laptops and smart phones connect to the internet which allows us to search for all kinds of information' (paper 12).

However, the dataset did not show a broad range of synonyms for 'technology'. There was some evidence of a tendency to repeat the superordinate instead of deploying a synonym. Excluding the use of the frequently used term 'computer(s)', given its denotation of a subset of technology as a whole, only eight out of 23 writers used direct synonyms for 'technology'. There were a total of 12 of these cases. This equates to just over one occurrence in every second paper. Although this seems like a low number, repetition of key words in academic texts is common, and 'technology in the classroom' was the central theme of the question.

\section{Lexical cohesion: exploring the term 'learner'}

The development of lexical fields around the term 'learner(s)' did not follow the same pattern as 'technology'. Instances of use of superordinate-level synonyms for the term 'learner(s)' 
were more frequent in the 23 texts. Excluding pronominal references, the number of writers using more than one word for 'learner(s)' or 'student(s) in the same text was 16 out of 23. There were, therefore, twice as many writers using synonyms in this field compared to 'technology'. While this may be due to the relative accessibility of high frequency alternatives to 'learner(s)' available to the writers, it does appear to be strong evidence of an awareness of the stylistic requirement for variation of key terms within a text. The conventions of English in this area do seem to be widely known and followed. This evidence runs contrary to the idea that transference from the oral traditions of isiZulu may influence these writers. Here are the frequencies of 'learner(s)' and associated synonyms across all 23 papers:

\begin{tabular}{|l|c|}
\hline Lexical item & No. of instances in data set \\
\hline Learner(s) & 81 \\
\hline Student(s) & 37 \\
\hline Children & 19 \\
\hline
\end{tabular}

\section{Substitution}

Examples of substitution using 'one/s', 'do', '(the) same' and 'so', which Halliday and Hasan (1976: 91) set out as the key substitutionary devices, did not appear in this dataset. There was only one example of substitution, as shown below:

'It also serve time for teachers to send their grading to district but they can use email to do that' (paper 7).

Such a low number of occurrences in the texts perhaps points to the need for input on how these words can used, with a view to producing denser text. Academic language input could draw attention to the use of substitution words like 'do' and 'so' to replace clauses and entire ideas. The potential value of this is illustrated in the extract below, where the writer produced a long run-on sentence which reads as somewhat unanalytical due in part to the way the writer repeated the distraction idea in three places:

'Learners will not use the technologies to do the school work only in the classroom an example would be when the learners are using the social media or application to communicate in the classroom they will talk about things which are not part of what they are learning and they can listen to music which is a big distraction in the classroom because learner or teaching happens when the teacher is teaching and the learners are listening without listening learning will not happen or will be distracted' (paper 23).

Here, this extract is rewritten in a more economic style with the inclusion of 'in doing so' as a substitutionary device:

One disadvantage of technology in the class is that it may be not be used solely for school work. An example of this would be learners using social media and listening to music instead of focusing on the lesson. In doing so, they are certainly damaging the learning process.

\section{Ellipsis}

The undergraduates' writing on technology was analysed for examples of ellipsis. Of the 23 papers analysed, only seven evidenced examples of ellipsis. Here is an example of this:

Per Linguam 2017 33(2):76-93

http://dx.doi.org/10.5785/33-2-700 
'Africa is the fasted growing mobile market and the second largest ... after Asia' (paper 16).

Given the low number of instances of ellipsis, there would seem to be potential for further development in this area. In fact, there were several points in the texts where entire [verb + complement] strings were repeated. The following example shows the kind of redundancy that can occur by such repetition:

'So I think that what I understand about this statement is that we should not rely on technology all the time as teachers we should identify the areas that needs technology the most and also identify those who need not be used with technology' (paper 6).

The following amended example shows how the language could be made more economical by ellipting the words after the negation:

What I understand about this statement is that we should not rely on technology all the time. Instead of this, we should identify the areas that needs technology and those that do not [...].

Academic language input on ellipsis could, for example, focus on providing exercises requiring the students to delete redundant language.

\section{Summary of findings}

Every paper in this dataset provided considerable evidence of the writer's skill with the use of cohesion in English. Some of the transfer errors considered likely to be found in the written English were not found to be prevalent. For example, a large majority of the uses of the definite article were correct and there were few double-subject errors. However, a significant number of determiner-based references were unclear and this is an issue that could be addressed. There were very few cases of conjunctions being used inaccurately according to the meaning apparently intended by the writer, although errors with the syntax surrounding the conjunctions were more common. However, the conjunction use in this dataset indicates further potential for developing control with the weighting of clauses in a more nuanced manner to give the writer's thought more explicit emphasis. This would help avoid long stretches of language that maintain a speech rhythm, where clauses are built upon on one another without clear emphasis.

Each paper evidenced a richness of cohesive links between various lexical items across the texts, including significant use of synonyms and hyponyms. There was less evidence of acquired strategies of ellipsis and substitution in their writing. Substitution with 'one', 'do', 'so' and 'do so' was almost non-existent and there were relatively few examples of ellipsis. Having said that, these two cohesive strategies are typically less frequent in writing than speech.

The table below summarises the areas that could be profitably addressed with academic language and writing skills input for isiZulu speakers, and is intended as a pragmatic response to the developmental possibilities revealed in the data:

\begin{tabular}{|l|l|}
\hline \multirow{2}{*}{ Reference } & \begin{tabular}{l} 
1. Clarify the use of the zero article. \\
\cline { 2 - 3 }
\end{tabular} $\begin{array}{l}\text { 2. Practise identifying ambiguous and non-ambiguous uses of 'this' as a } \\
\text { reference. }\end{array}$ \\
\hline
\end{tabular}

Per Linguam 2017 33(2):76-93

http://dx.doi.org/10.5785/33-2-700 


\begin{tabular}{|c|c|}
\hline & $\begin{array}{l}\text { 3. Encourage increased frequency and specificity of [this + noun] structures } \\
\text { with abstract nouns, e.g., 'this idea, this principle, this process, this } \\
\text { approach', to refer to whole stretches of earlier language; to facilitate the } \\
\text { production of more lexically dense text. }\end{array}$ \\
\hline \multirow{4}{*}{ Conjunction } & $\begin{array}{l}\text { 1. Develop the use of contrastive conjunctions, linked to the role of forming } \\
\text { counter-arguments. }\end{array}$ \\
\hline & $\begin{array}{l}\text { 2. Compare the use of coordinating and subordinating conjunctions in order } \\
\text { to illustrate how to emphasise and give prominence to one clause over } \\
\text { another and reduce instances of run-on sentences. }\end{array}$ \\
\hline & $\begin{array}{l}\text { 3. Develop the following cohesive devices: } \\
\text { Conjunction + determiner: e.g., Because of this... } \\
\text { Conjunction + determiner + abstract noun: e.g., Despite this policy... } \\
\text { Reference + abstract noun + conjunction: e.g., This inflation is due to... } \\
\text { Determiner + linking verb + conjunction: e.g., This was in spite of... }\end{array}$ \\
\hline & $\begin{array}{l}\text { 4. Practise identifying fragment sentences to reinforce required syntax } \\
\text { around some conjunctions. }\end{array}$ \\
\hline Substitution & $\begin{array}{l}\text { 1. Give examples and practice of substitution of verbs and clauses with 'do', } \\
\text { 'so' and 'do so'. }\end{array}$ \\
\hline Ellipsis & $\begin{array}{l}\text { 1. Provide opportunities to practise nominal and verbal ellipsis by asking } \\
\text { students to identify parts of a sentence that can be removed to reduce } \\
\text { redundancy. }\end{array}$ \\
\hline
\end{tabular}

\section{DISCUSSION}

The suggestions set out above deal with technical language skills. They are located within the 'study skills' model of academic literacy which 'sees writing and literacy as primarily an individual and cognitive skill ... [and] focuses on the surface features of language form' (Lea \& Street, 2006: 228). It is not my intention to suggest, however, that only technical language skills should be addressed during academic language input. It would, in fact, be desirable that at least equal attention be paid to process approaches to writing, allowing for writers to explore meaning-making more freely, along with increasing the knowledge required to participate in the discourses of a student's particular subject specialism.

The suggested input on technical language skills would certainly have been valuable to the 23 students whose writing has been investigated in this paper. Clearly, though, it is difficult to generalise from this small sample about how applicable these suggestions would be to all isiZulu speakers writing academic English. However, the results given here could be a reference for further larger studies. Moreover, the above suggestions could lead to the development of a set of materials which could be deployed following a needs analysis to determine specific individual needs. It would also be instructive to see how consistent these findings would be with those arising from comparable data from other Nguni language users writing in English, given the similarities between isiZulu and isiXhosa, for example. This would potentially allow for the development of institutional strategies capable of benefiting a larger number of students.

While the stance of this paper is that the academic English of a particular group of isizulu speakers could be developed with respect to cohesion, there is an ongoing debate within South Africa about the suitability of English as an academic medium of instruction for speakers of 
other first languages (Foley, 2004; Van Der Walt, 2004). The development of isiZulu and other African languages as academic languages could be a vital part of raising rates of achievement, allowing mother-tongue speakers to capitalise on existing fluency at every stage of their education. Moreover, since literacies can be considered 'an essential part of a person's conception of his/her culture and personhood' ( $\mathrm{Li}, 2000$ : 10), promoting the dissemination and generation of advanced academic knowledge in African languages may also contribute to decolonisation (Phillipson, 1996). However, at present South African universities seldom, if ever, offer courses with African language media of instruction so it is hoped that the research presented here might contribute to academic language input so long as the status quo persists.

\section{CONCLUSION}

This study has generated knowledge on how cohesion was being used by a group of isiZulu speakers at Wits University. Knowledge of this has implications for isiZulu speakers in tertiary education across South Africa and has led to suggestions on how academic language input could facilitate writing skills development for this language group. A pragmatic response to these findings has been provided in the form of a set of suggestions to develop language skills in the area of cohesion.

\section{REFERENCES}

BIBER, D. 1993. Using register-diversified corpora for general language studies. Computational Linguistics, 19(2):219-241.

BUTLER, HG \& TJ VAN DYK. 2004. An academic English language intervention for first year engineering students. Southern African Linguistics and Applied Language Studies, 22(1-2):1-8.

CLARENCE-FINCHAM, J. 2000. Cummins' contribution to the understanding of language learning and achievement at school. In Inglis, M, C Thomson \& A Macdonald (Eds), Language in learning and teaching. Pietermaritzburg: University of Natal Press. 141145.

CRYSTAL, D. 2011. Dictionary of linguistics and phonetics (Vol 30). London: Wiley.

DRUMMOND, A. 2016. An investigation of noun frequencies in cohesive nominal groups. Journal of Second Language Teaching \& Research, 5(1):62-88.

FANG, Z, M SCHLEPPEGRELL \& B COX. 2006. Understanding the language demands of schooling: nouns in academic registers. Journal of Literacy Research, 28(3):247-273.

FOLEY, A. 2004. Language policy in higher education in South Africa: implications and complications: perspectives on higher education. South African Journal of higher education, 18(1):57-71.

GEE, JP. 1990. Social linguistics and literacies: ideology in discourses. London: Routledge.

GUTIERREZ-CLELLEN, VF \& L HEINRICHS-RAMOS. 1993. Referential cohesion in the narratives of Spanish-speaking children: a developmental study. Journal of Speech, Language, and Hearing Research, 36(3):559-567.

HALLIDAY, MK \& R HASAN. 1976. Cohesion in English. London: Longman.

HALLIDAY, MK. 1994. An introduction to functional grammar. London: Routledge.

HLONGWANE, JB, \& JA NAUDÉ. 2004. The rhetorical forms of Henry Rider Haggard's Nada the Lily in Zulu. Southern African Linguistics and Applied Language Studies, 22(1-2):9-25.

HYLAND, K. 1994. Hedging in academic writing and EAP textbooks. English for Specific Purposes, 13(3):239-256.

Per Linguam 2017 33(2):76-93

http://dx.doi.org/10.5785/33-2-700 
JISA, H. 2004. Growing into academic French. In Berman, RA (Ed), Language development across childhood and adolescence. Amsterdam: John Benjamins. 135-162.

LEA, MR \& BV STREET. 2006. The 'academic literacies' model: theory and applications. Theory into Practice, 45(4):368-377.

LETSEKA, M \& S MAILE. 2008. High university drop-out rates: a threat to South Africa's future. Pretoria: Human Sciences Research Council.

LI, G. 2000. Family literacy and cultural identity: an ethnographic study of a Filipino family in Canada. McGill Journal of Education, 35(1):9-29.

LINELL, P. 2004. The written language bias in linguistics: its nature, origins and transformations. London: Routledge.

MAKALELA, L. 2007. Nativization of English among Bantu language speakers in South Africa. Issues in Applied Linguistics, 15(2):129-147.

MAKALELA, L. 2015. Moving out of linguistic boxes: the effects of translanguaging strategies for multilingual classrooms. Language and Education, 29(3):200-217.

MOHAMED-SAYIDINA, A. 2010. Transfer of L1 cohesive devices and transition words into L2 academic texts: the case of Arab students. RELC Journal, 41(3):253-266.

NDLOVU, MV. 2009. The accessibility of translated Zulu health texts: an investigation of translation strategies. Unpublished $\mathrm{PhD}$ thesis, University of South Africa, Pretoria.

NDLOVU, MV. 2013. Referential cohesion in isiZulu translated health texts. Southern African Linguistics and Applied Language Studies, 31(3):349-357.

NZAMA, MV. 2010. Error analysis: a study of errors committed by isiZulu speaking learners of English in selected schools. Unpublished $\mathrm{PhD}$ thesis, University of Zululand.

PHILLIPSON, R. 1996. Linguistic imperialism: African perspectives. ELT Journal, 50(2):160-167.

SIMMONS, AM. 2015. Responsible grammar rebels. Journal of Adolescent \& Adult Literacy, 59(4):387-395.

SOUTH AFRICAN MINISTRY OF EDUCATION. 2002. Language Policy for Higher

Education. Available from

http://www.dhet.gov.za/HED\%20Policies/Language\%20Policy\%20for\%20Higher\%20Educat ion.pdf [Accessed: 4 February 2015].

SPACK, R. 1988. Initiating ESL students into the academic discourse community: how far should we go? Tesol Quarterly, 22:29-51

STATISTICS SOUTH AFRICA. 2011. Census 2011: census in brief. Available from http://www.statssa.gov.za/census2011/Products/Census_2011_Census_in_brief.pdf [Accessed: 25 January 2015].

STOTSKY, S. 1983. Types of lexical cohesion in expository writing: Implications for developing the vocabulary of academic discourse. College Composition and Communication, 33(4):430-446.

TAYLOR, N \& P VINJEVOLD. 1999. Teaching and learning in South African schools. In Taylor, N \& P Vinjevold (Eds), Getting learning right. Report of the President's Education Initiative Research Project. Witwatersrand: Joint Education Trust. 138-191.

VAN DER WALT, C. 2004. The challenge of multilingualism: in response to the language policy for higher education: perspectives on higher education. South African Journal of Higher Education, 18(1):140-152.

WALT, JL \& BV ROOY. 2002. Towards a norm in South African Englishes. World Englishes, 21(1):113-128.

Per Linguam 2017 33(2):76-93

http://dx.doi.org/10.5785/33-2-700 
WINGATE, U \& C TRIBBLE. 2012. The best of both worlds? Towards an English for Academic Purposes/Academic Literacies writing pedagogy. Studies in Higher Education, 37(4):481-495.

\section{BIOGRAPHICAL NOTE}

Andrew Drummond is an English for Academic Purposes tutor at King's College in London. He formerly studied and worked at Wits University in Johannesburg.

Email andrew.drummond@kcl.ac.uk 